\title{
Poética y política en el reino de la primera infancia, y de sus maestras. Conversación con Yolanda Reyes
}

\author{
Poetics and politics in the realm of early childhood and its teachers. \\ A conversation with Yolanda Reyes

\section{Sarah Flórez Atehortúa*} \\ (iD https://orcid.org/0000-0002-6021-0398
}

Tipo de Artículo: Entrevistas

Doi: 10.17533/udea.unipluri.20.2.021

Flórez Atehortúa, S. (2020). Poética y política en el reino de la primera infancia, y de sus maestras. Conversación con Yolanda Reyes.Uni-Pluriversidad, 20(2), e20202021. doi: 10.17533/udea.unipluri.20.2.021

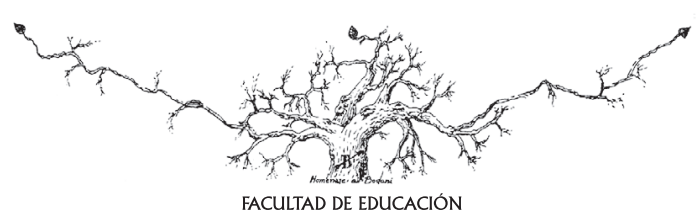

* Jefa - Departamento de Educación Infantil. Universidad de Antioquia, Colombia. Email: sarah.florez@udea.edu.co 


\title{
Resumen
}

Este artículo recorre algunos hitos de la biografía y trayectoria intelectual, política y académica de la escritora, columnista y educadora colombiana Yolanda Reyes. En él se desarrollan, de viva voz y a través de una conversación, las experiencias, preocupaciones y acciones que la condujeron a formar parte de una movilización que ha contribuido a trazar en el tiempo presente los sentidos y las formas de la educación inicial en el país. Su itinerario parte de la preocupación por los procesos que inauguran la formación en la lectura y la escritura en las instituciones escolares, discute las prácticas que priman en ese territorio y, a través del descubrimiento del universo de la literatura infantil y de sus efectos en los niños y las niñas, formaliza su apuesta por la comprensión del estímulo poético en la primera infancia como "nido" para el aprendizaje formal de la lectura y la escritura. Lo anterior la conduce a profundizar en la reflexión y en el ejercicio de formar a las maestras que trabajan en educación infantil -considerando de manera especial su mundo subjetivo-, y a incursionar en el territorio de las políticas públicas como escenario para interrumpir y revertir la brecha que las injusticias sociales producen en este momento fundante de la vida y de las relaciones con el saber. Finalmente, menciona el valor que tiene la existencia de orientaciones o lineamientos para acompañar el hacer de quienes trabajan directamente con los niños y las niñas, y plantea la necesidad de centrar las acciones venideras en la formación y el trabajo en "terreno".

Palabras clave: poética, política, primera infancia, educación infantil, literatura infantil, formación de maestras

\begin{abstract}
This article presents some milestones in the biography and intellectual, political and academic career of the Colombian writer, columnist and educator Yolanda Reyes. Through an open conversation, this article presents concerns and actions that led her to be part of a mobilization that has contributed to trace the current meanings and forms of early education in the country. Her journey starts with the concern for the processes to begin training in reading and writing in school institutions. She discusses the practices about it and, through the discovery of the universe of children's literature and its effects on children, she formalizes her commitment to understand the poetic stimulus in early childhood as a "nest" for the formal learning of reading and writing. It takes her to go deep in the reflection and the exercise of training teachers who work in early childhood education -considering especially their subjective world- and to enter the territory of public policies as a stage to interrupt
\end{abstract}


and close the gap that social injustices produce in that founding moment of life and relationships with knowledge. Finally, she mentions the value of the guidelines that direct the actions of those who work directly with children, and she raises the need to focus future actions on training and "field" work.

Keywords: poetics, policy, early childhood, early childhood education, children's literature, teacher training. 


\section{INTRODUCCIÓN}

Este texto ${ }^{1}$ es el fruto de una conversación que generosamente Yolanda Reyes aceptó sostener en el marco de una investigación orientada al reconocimiento de las trayectorias y desafíos en la implementación de la política pública de primera infancia en Colombia ${ }^{2}$-De Cero a Siempre- y de una investigación doctoral que aborda -a partir del caso colombiano- la tesis de la educación de la infancia como problema político.

La conversación tuvo lugar luego de conocer la participación de esta escritora y educadora en la composición de los fundamentos pedagógicos de la política pública nacional De Cero a Siempre, antecedida por sus aportes en la ciudad de Bogotá y por una amplia trayectoria relacionada con la formación de lectores a través de la literatura infantil.
El deseo de reconocer las historias detrás de quienes han contribuido en la construcción de lineamientos, orientaciones y políticas sobre la educación infantil, que en apariencia se nos presentan como neutrales, hizo lugar a este relato en el que la literatura infantil oficia indiscutiblemente como agalma y como alma del camino labrado por Yolanda Reyes. Las consecuencias e incidencias de sus decididas búsquedas y elaboraciones son evidentes y trascienden tanto la geografía nacional como el territorio de la educación de la primera infancia. Su convencimiento acerca de las repercusiones de las políticas y de la poética en el acontecer de las vidas de los niños y las niñas, de las maestras y del mundo común, mantienen viva su pluma que interpela la responsabilidad de quienes toman decisiones en relación con las políticas, cuestiona, inspira y desafía a quienes enseñan, y crea relatos que cuidan y cultivan la imaginación de los recién llegados.

\section{Conversación}

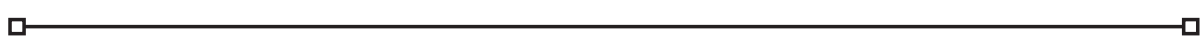

Yolanda Reyes: aquí, parte del problema es la falta de institucionalidad de las cosas; que siempre dependen de quién esté por ahí.

Entonces, ¿qué quieres de mí?

Sarah Flórez: busco comprender el contexto de construcción de la política De Cero a Siempre, particularmente la producción de la idea de educación inicial. Algunas de las preguntas que le propongo para este intercambio son las siguientes: ¿cuál es su historia de relación con el campo de la educación inicial?, ¿cuál y cómo ha sido su participación en la construcción de los lineamientos de la política? y ¿cómo ha vivido usted ese proceso?

Yolanda Reyes: empecemos por la historia. ¿Por qué llegué yo a la educación inicial? Estudié Ciencias de la Educación, me especialicé en Literatura y desde el comienzo de mi trabajo nunca supe bien qué era más importante para mí: si escribir y la literatura, o trabajar en educación a partir de la literatura. 
La historia mía, de hecho, se parece un poco a la de Graciela Fandiño. Trabajé en colegio, después me fui muy por el lado del acercamiento a la lectura, de la formación de lectores, y ahí la literatura fue muy importante. Y trabajé en la Fundación Rafael Pombo -en Bogotá-, monté la biblioteca infantil, que fue -te estoy hablando del milenio pasado- en 1986, y a partir de esa biblioteca empezó toda mi preocupación por la primera infancia. ¡Porque, claro!, yo había sido profesora de colegio, hablaba como todos los profesores hablamos del problema de la lectura, después llegué a esta biblioteca a mirar el asunto de la literatura desde otro lugar: el deseo de leer, las ganas de leer, la lectura fuera del contexto escolar, fuera de la obligatoriedad.

Esa biblioteca fue la primera con estantería abierta, donde los niños podían jugar, divertirse, leer espontáneamente, y -bueno, la Biblioteca Pública Piloto siempre fue un referente para nosotros- en Bogotá no había una opción de una biblioteca donde sucedieran muchas cosas culturales. Nosotros armamos ese proyecto con un grupo de gente - todos muy jóvenes- y empezamos a ver que la biblioteca estaba pensada para los niños que sabían leer o que estaban aprendiendo; y en el milenio pasado, esos niños eran los que iban a la escuela básica primaria.

De hecho, en esa época, el preescolar no era obligatorio, el "grado cero" empezaba como a estar en los primeros discursos, pero la educación empezaba en primer grado. Y eso, para efectos de la lectura y de la escritura, era dramático porque ahí en la Pombo yo me di cuenta -la primera vez que tuve conciencia clara de la gran brecha entre los lectores, que tiene todo que ver con la brecha educativa, porque si tienes dificultades para leer todo se va enredando a lo largo de la primaria y la secundaria, y cada vez se enreda más-, lo que descubrí ahí o lo que empecé a vislumbrar o se volvió una hipótesis, era que los niños que tenían acercamiento a formas literarias, a libros, a todas las manifestaciones de la lengua escrita -incluyendo los relatos orales-, todo el estímulo de las palabras, todo el estímulo poético que hay en la primera infancia -la canción de cuna, los juegos de palabras, todo ese repertorio-, eso se daba por lo general en contextos privilegiados, en preescolares privados o en familias con un nivel cultural X; eso era como un colchón -un nido le llamé yo- para el aprendizaje formal de la lectura y escritura. Entonces pensé: “ ¿y desde cuándo somos lectores?" Porque en la Fundación Rafael Pombo, ¡claro!, mi biblioteca era para niños que sabían leer o estaban aprendiendo, y eso significaba 7 años para arriba, 6 años, los de abajo de esa edad no cuadraban.

Sin embargo -como suele suceder en todas las historias-, pues había unos lectores que se colaban ahí en esa taxonomía: y la mamá que decía: "voy aquí al Ley, y ¿puedo dejar este chiquito aquí un rato? Y usted me lo mira, él se porta bien"; y yo: "pues, ¡déjelo!". Y empecé a trabajar con niños que no eran los que la biblioteca esperaba y a descubrir las mil formas de lectura que había en estos chiquitos. Y, además de las mil formas de lectura, el enorme placer que todavía para ellos significaba el encuentro con el libro y con la palabra, que era completamente opuesto a lo que me pasaba con los niños escolarizados que iban a mi biblioteca y a los que yo tenía que convencer con carreras de observación a ver si encontraban un libro, bueno, y corríamos... Tenía que desescolarizar todo, casi que mandar a veces a los profesores a que se tomaran un café al lado y me dejaran a los niños un rato sin la obsesión por saber cuál era la idea principal y la 
secundaria, qué habían leído, por qué habían leído y toda esa parafernalia relacionada con la alfabetización, con la escolarización de la lectura.

Y al descubrir que había - digamos- un paraíso de la lectura, que era anterior a ese momento, y donde se formaban las cosas más importantes: la conciencia lingüística, la conciencia semántica, o sea, saber cómo cantan las palabras, cómo suenan cuando uno baila con los pies... Y Teresa la Marquesa, y Materile, y las rondas, y ver que todo ese acervo estaba ahí, lo primero que yo pensé fue: "yo tengo que trabajar con maestras antes de la catástrofe". Y la catástrofe -pensaba yo- es cuando la lengua se vuelve objeto de disección alfabética, o sea, todo ese momento en el que hay que aprender a leer y a escribir, que estaba situado en Primero de primaria. Y los profesores odiaban Primero, a los más subversivos los mandaban a Primero porque había una carga terrible que era que los niños no sabían leer cuando llegaban y al final tenían que saber leer. Primero era el agujero negro; como si antes de Primero no hubiera pasado nada con la lengua, con la conciencia lingüística, y como si después no siguiéramos aprendiendo a leer y a escribir.

Entonces dije: “¿dónde se rompe esto?”, inmediatamente pensé: "¡hay que formar maestras de preescolar!" -se llamaba en ese momento-; nadie hablaba de educación inicial. "Hay que formar maestras de preescolar para que hagan todo este nido de sentido, hagan toda esta maravilla y trabajen con los niños antes de la alfabetización", que era como una pavimentación de la lengua. Y, se me ocurrió pedir trabajo en la Universidad Pedagógica Nacional, en el programa de preescolar. Tuve mucha suerte porque estaba muy obsesionada con esto y fui donde Inés Elvira Castaño -que fue una persona muy importante, se murió desafortunadamente- y le dije -alguien me consiguió una cita-: "imire! Yo estoy trabajando en esto y a mí me parece que todo el acercamiento a la literatura tenemos que hacerlo aquí, pero no hay cátedras de literatura infantil en las universidades, las futuras maestras no tienen cercanía con la literatura para niños".

Al mismo tiempo que eso pasaba, ¡claro!, también soy escritora y estábamos en toda esta movida del descubrimiento de la literatura infantil, de los libros álbum, de todo lo que esto significaba para el desarrollo de la imaginación, de la creatividad, y estábamos apasionadas por esto, y creo que fue eso lo que a mí me llevó a decirle a Inés Elvira Castaño: "por favor déjeme pasarle una propuesta de literatura infantil para dar en el programa de preescolar", y ella me dijo: "pásemela". La pasé y entré. Al mismo tiempo, había un grupo muy interesante -muy marginal por supuesto-: estaban los que hablaban de epistemología y filosofía, y por ahí estábamos Julia Rodríguez -que hacía teatro y títeres toda la vida, una mujer que fue pionera en eso, ya se murió-, Teresita Lleras en artes plásticas, estaba yo en literatura y había alguien en música, y empezamos a poner las artes en la canasta curricular de este programa de preescolar, y a ver cómo eso abría un pensamiento disidente, un pensamiento sensorial... Muchas alternativas lúdicas, pero en el sentido fuerte.

Sarah Flórez: en el sentido serio...

Yolanda Reyes: en el sentido serio y profundo de esta otra manera de mirar el mundo, de construir símbolos y cómo eso era importante. Y ya creo que te puedo decir una cosa, que es cómo era de importante, no para la primera infancia, sino para las maestras que estaban ahí, para ellas como perso- 
nas. Yo creo que desde eso a mí me entró la ventolera de montar Espantapájaros. Cuando quise estudiar pedagogía sí miré lo de preescolar - para mí como niña estudiante-, y hacían frisos, unas cosas como de papel... cartulinas, y era un mundo tan pequeño que me salí de ahí corriendo, me fui a literatura y volví, pero volví con esta idea, y ese fue el comienzo de todo el trabajo, de los encuentros con colegas. De ahí -después de la Pombo y de la Pedagógica-, yo seguí trabajando en la Pedagógica formando maestras en literatura, gente que todavía anda por ahí.

Mis primeras alumnas me las encuentro y me conmuevo muchísimo de verlas, porque creo que todos los que nos encontramos en ese momento con la literatura infantil tan maravillosa, tan fuerte, tan transgresora, como que la vida nos dio un vuelco. Y ahí fundamos Espantapájaros. Al principio tenía solo una propuesta de talleres: arte, literatura, música; y tenía una propuesta de formación de maestros; lo que hacíamos era tratar de desestigmatizar esa idea de la lectura como una carga, una obligación, una tortura, toda esa tragedia de "la letra con sangre entra" y abrirle la puerta a todo lo que empezaba a pasar en la literatura para niños -en Colombia y, por supuesto, todo lo que venía de afuera-. En un momento ya estaba Espantapájaros -este lugar donde tú estás-, estaba montado y nosotros sentíamos que hacía falta algo, y lo que sentíamos que hacía falta era la permanencia de los niños; dijimos: "montemos un jardín infantil". Pero “¡Dios mío! ¿Un jardín infantil cómo?”. Un jardín infantil centrado en el arte y la literatura, esa fue la pista. "Nos vamos a meter por ahí, ¡con una súper divina biblioteca, los niños mordiendo libros!". Con una apuesta cultural muy fuerte y con mucho arte: música, artes plásticas, todo el desarrollo perceptual a partir del arte, cocinar, brincar, saltar, moverse con todo el cuerpo, oler, probar, tocar y explorar.

Al principio, pues obviamente los niños estaban un tiempo y las mamás se los 1levaban a un sitio donde les enseñaran a picar por la línea -y esas cosas-, a colorear sin salirse y todo este horror... Que aquí las planas “ ¿dónde estaban?” Te estoy hablando del año 1990, la gente solía decir: "esto está muy bueno, los niños están felices pero la vida no es así. Chao, nos vamos". Ahí empezaron a pasar varias cosas: por un lado, esto de que los niños estaban un tiempo, pero había que escolarizarlos. La obsesión escolarizadora -que todavía continúa- yo creo que es una marca de todos los estratos y de todas las culturas en este país. Todo el mundo está obsesionado, desde un hogar del ICBF -entras y ves la obsesión por las planas y los números- hasta el jardín infantil más sofisticado. Ese fue uno de los problemas. Y el otro gran problema que empecé a tener $y$ al que quise responder -sigo queriendo responder, han pasado 30 años y nada está resuelto- era el de la formación de las maestras. ¿Quiénes me llegaban aquí?, ¿con quién podía yo trabajar? y ¿qué tenía que enseñarles?, pero también $-\mathrm{y}$, sobre todo¿qué tenía que des-enseñarles?

Habían ido a la Universidad, entonces empecé a pensar: psicólogas, pedagogas; yo tenía mi banda de alumnas de la Pedagógica y pues también tengo formación de educadora, entonces me interesaba la educación -por supuesto- y me interesaba que fueran pedagogas. Pensaba también que hubiera una conversación muy interdisciplinaria entre la psicología y la pedagogía, sobre todo con los chiquitos; y que de todas maneras hubiera un apoyo en profesionales de otras disciplinas: las terapias, etc. Había un denominador común en todas las profesiones: era la ausencia casi total de formación en 
imaginación, creatividad, desarrollo artístico. Sentía que lo otro era más fácil, darle un libro a la gente, darle una línea o darle un enfoque pero que había que hacer un trabajo muy desde adentro, rompiendo muchas cosas que uno tiene puestas desde antes de haber entrado a la Universidad, que hacen parte del equipaje de lo que pensamos qué es educación y de lo que pensamos qué es infancia.

Y ahí empecé a trabajar y ese ha sido mi trabajo obsesivo durante todos estos años, que son ya fácilmente 30 años. Empecé a hacer ponencias sobre esto, también a plantearme la idea de montar una biblioteca para la primera infancia y de ver qué pasaba con los niños. Y empezar a ver, y a ver, y a ver y a ver cosas cada vez más impresionantes de cómo los bebés leían, de cómo se comían los libros, de qué significaba tener ese baño de palabras alrededor, de qué significaba para las familias tener eso. Mejor dicho, de cómo se construía el sentido de la vida en esos pequeños acercamientos y empezar a ver el comportamiento de los niños, y todo lo que pasaba. Y, empezar a ver también una cosa muy impresionante que era la brecha, en la medida en que yo trabajaba más, sentía que más contribuía a ampliar la brecha, y eso era terrible porque estos niños con este acceso a los libros, a las artes, con esta conciencia de quienes son y con criterio; creo que los niños desde muy chiquitos van formando su criterio, sus posibilidades de expresión, la creatividad. Yo decía: "voy a aprender mucho de ellos y voy a empezar a escribir sobre esto, a escribir y a hacer una especie de proselitismo político para poderme colar en otros escenarios y que me crean; pero yo tengo que tener algo", porque era un lenguaje un poco intuitivo - por un lado- $y$, por otro lado, poco acompañamiento teórico, no había hacia dónde mirar.
Entonces, bueno, "ipues hay que escribir!" Y empecé a escribir lo que pasaba y empecé también a crear mecanismos de recolección de la información: vídeos, escritos... ¡Claro! Soy escritora, entonces a mí me daba vueltas la cabeza, porque esto es una locura, todo lo que pasa, todo lo que puedes descubrir ahí en arte y literatura. Y empecé también -obsesivamente- a pensar que esto tenía que volverse político. O sea, que la poética y la política estaban muy cerca, y que había que tocar esas puertas.

Con Graciela Fandiño siempre habíamos sido colegas -justamente por estar relacionadas con los libros para niños-, y en el momento en que ella entró a la Secretaría de Integración Social de Bogotá -delegada por la Universidad Pedagógica- yo ya había escrito mucho sobre esto, viajaba por toda América Latina hablando de bibliotecas de la primera infancia, ya tenía libros publicados y Graciela me dijo: “¿por qué no hace la parte de literatura y mira un poco lo de arte? Lo miramos".

Esto era con Constanza Alarcón ${ }^{3}$, ahí me acerqué mucho a ella y cuando se fue a la Comisión Intersectorial de primera infancia dijo: "ustedes ya hicieron lo de Bogotá, ahora hagamos lo de Colombia -con el Ministerio de Educación-". Ahí yo también volví a trabajar en la parte de literatura. Y por todos lados lo que hemos estado tratando de hacer es dar un poco de lineamiento; en literatura no hay mucho escrito -la verdad-, en otros países tampoco hay mucho avance, y esto ha sido lo mío y he tratado de compartir lo que sé, de moverme, de crear redes, hasta ahora que uno siente que ya hay mucha gente trabajando en eso...

Sarah Flórez: ¡sí! El tema está muy posicionado ya... 
Yolanda Reyes: exacto. Y que ya nos están creyendo, porque eso no es tan fácil. Y bueno, esa es la historia, ese es el cuento.

Sarah Flórez: en las trayectorias que ha tenido la educación infantil, parece haber una tensión entre lo que usted llama escolarización - una perspectiva que busca que con los niños y las niñas se realice un trabajo de aprestamiento, que aprendan y puedan ser evaluados- y una propuesta educativa basada en la sensibilidad, en la imaginación, en la creatividad, en el vínculo con la cultura -que es la que usted sostiene-. ¿Por qué cree que es importante que un niño lea, se acerque al arte y a todas estas manifestaciones de la cultura?

Yolanda Reyes: voy a hablar primero de lo útil -esto me suena casi a herejía decirlo-, pero es que el arte es necesario, creo que más que nunca en primera infancia. Todo el desarrollo perceptual: el hecho de mirar, sentir, tocar, probar, amasar, no solo es un goce sensorial -que ahí nos conectamos con el sentido del arte-, sino que también es una necesidad perceptual y de desarrollo. El lenguaje del arte en la primera infancia, yo diría que es muy cercano a los niños: los niños cantan, bailan, saltan, suenan, se fijan en la materialidad de los signos, en la materialidad de la sonoridad, se fijan en los colores y se fijan en la materialidad de las palabras. Cómo suenan las palabras, no qué dicen, les importa más la música que la letra, juegan con eso, necesitan conquistar el lenguaje y hablar también implica apropiarse de esas etiquetas, gozarlas y reelaborarlas.

En toda esa reelaboración sensorial y simbólica -que es propia del arte-, los niños están desarrollándose. O sea, es esencial para el desarrollo de la primera infancia -por un lado-. Pero, además, por otro lado -creo que no es otro lado, es el mismo lado-, la vida afectiva, lo que permite la vinculación con la cultura, lo que se mueve por otros canales que no son los de la racionalidad, y los niños necesitan crecer en esos otros canales, en esos otros lenguajes y esa es la manera de vincularse. Un niño se vincula sensorialmente a una mamá que lo mece, que lo contiene, que lo abraza, y todo esto de la piel, todo esto del canto, es parte de su desarrollo afectivo, es parte fundante. Por otro lado, el arte -desde la primera infancia- abre las puertas a que las respuestas sean distintas. Y eso es muy importante, no solo para la no escolarización idéntica de todos, sino para la posibilidad de abrirse a la diversidad regional.

El primer arte de un niño que es su lengua materna, su entorno cultural, le da noticias de que el mundo es diverso, le da noticias de un arraigo que pasa por lo sensorial, por lo estético -y que es distinto-; yo creo que ahí hay una gran promesa de interculturalidad. ¡Se habla tanto del "respeto por lo territorial y el enfoque diferencial"! No hay nada más diferencial que el canto de una lengua, que los ritos de dormir, que los tambores; ahí está la cultura circulando, y eso es lo que mama un niño en la primera infancia. Yo creo que ahí está el arte.

Sarah Flórez: una última pregunta porque sé que tiene un compromiso-: ¿cuáles son para usted los desafíos que tiene formar desde esa perspectiva a quienes hoy se les llama "agentes educativos" y a las maestras en general? Puede suceder que esto se instrumentalice, y sin duda, escuchándola, de lo que se trata es de una apertura hacia el contacto con la cultura...

Yolanda Reyes: sí. Las receticas.

Sarah Flórez: ¿Cuáles son los desafíos que tenemos por delante? El trabajo con 
maestros, maestras y con quienes están con los niños y las niñas para que se pueda poner en marcha algo de esta transmisión...

Yolanda Reyes: sí, que no se vuelva la receta: "primero abra el libro y después siente a los niños en círculos", aunque requiera -de todas maneras- de los ritos propios de las disciplinas y de los encuadres que son necesarios en la primera infancia.

El desafío es que el trabajo tiene que arrancar con los sujetos mismos que están en las Facultades de Educación. Pienso que eso que hicimos en la Universidad Pedagógica de vincular a la gente con el arte, no hacer una clase de "hora del cuento para los niños", el cuento para ti. Obviamente, después tengo que mirar esto cómo lo trabajo: “¿cómo lo hago?”, "cómo esto que yo sé y que yo siento, ¿cómo hacerlo con los niños reales?"

Por eso, yo creo que la formación tiene que partir de otro lado; si no somos lectores y si no hemos descubierto eso... Eso se puede hacer en las Facultades, ¡se puede hacer!, pero implicaría revisar esta obsesión porque, fíjate que incluso desde los lineamientos o las orientaciones, la obsesión sigue siendo por las actas, por "la sistematización". El arte tiene otras maneras de ser construido, de ser pensado y de ser transmitido; si se puede hablar de transmisión cultural -que creo que sí-.

Creo que un gran reto es formar gente por todas partes. Hacer programas pequeños de formación con agentes educativos, madres comunitarias, no es tan difícil. Pero implica volver a: "siéntese en el piso, empiece a mirarse por dentro y empiece a mirar quienes están al lado suyo -que son estos muchachitos-". Y creo que las orientaciones son importantes. Si hubiera que escoger en- tre la receta de la hora del cuento y las recetas anteriores, me quedaría -aun así- con la idea del rito vinculante de que haya libros en el salón, ique no son recetas en el fondo! Un rito de leer a viva voz con los niños ¡no es una receta! Hay que sacarlos de ahí, pero no son recetas, son propuestas. A veces no puedes soltar todo como tan en abstracto. Entonces creo en las orientaciones pedagógicas, creo en la pedagogía, ipor supuesto!

Sarah Flórez: gracias, creo que está muy bien así...

Yolanda Reyes: ¿te parece?

Sarah Flórez: sí. Entender qué reflexiones hay en la base de esas apuestas por posicionar arte, juego y literatura en la educación infantil es parte de mi búsqueda y usted me ha ayudado en ello.

Creo que está bien, salvo si usted quiere compartirme cómo ve el desarrollo de la Estrategia De Cero a Siempre en términos de lo que ahí se aborda como educación inicial. He visto en algunos de los materiales que usted comparte ciertas preocupaciones por prácticas difíciles de desplazar en el nivel.

Yolanda Reyes: falta mucho.

Sarah Flórez: ¡tenemos mucho trabajo por delante!

Yolanda Reyes: sí. Creo que con todo el problema que puedan tener los lineamientos -que seguramente los tienen- y, además, cómo pasas todo esto a papel: hay una cantidad de funcionarios mirando si dices los niños, las niñas, si quitas, si pones, si el lenguaje es políticamente correcto, en fin, todo eso puede pasar. Pero siento que este es el tiempo de hacer cosas en terreno, creo que este es el tiempo de aprender en el terreno 
de la primera infancia, ese es un reino y ahí hay que meterse con todo. Hay que meterse en el ICBF, en la vida real en donde suceden las cosas y ahí hacer camino al andar.

Yo diría que no más lineamientos, ¡hagamos! Ya hay una pequeña brújula, y sí, cualquiera puede hablar de jugar para saber más colores, y por literatura también puedo entender la fábula por moraleja para que los niños se porten bien... Pero en los lineamientos hay un horizonte. Lo que hay que hacer ahora es formar y trabajar en terreno.

Sarah Flórez: Muchas gracias.

\section{CONSIDERACIONES FINALES}

Los derechos del niño tienen un único significado:

manifiestan el compromiso de los adultos para que cada niño pueda, un día, firmar su propia vida.

(Meirieu, 2004, p. 42)

Si ensayamos un parafraseo de ese enunciado en apariencia solitario que da inicio a la conversación aquí compartida, podríamos decir: "las cosas, cuando se trata de la infancia, de la educación y de las políticas, dependen de quién esté por ahí". Es la presencia la que hace institución, la que permite desplegar y sostener unos gestos educativos y abrirle lugar en las políticas al compromiso que ello representa. Esa presencia instituyente de otras realidades, de comienzos y devenires justos, tiene entre sus formas más sensibles la lectura. Leer a la infancia, leer la infancia, disponerse a ser leído por la infancia, leer con la infancia; gesto generoso, desafiante, que tiene entre sus funciones como nos lo enseña Yolanda- la interrupción de las brechas que expulsan a algunos de ese reino que es nuestra responsabilidad hacer existir y cuidar para los más pequeños.

¿Qué resulta del hecho de nombrar a la primera infancia como un reino? Es claro que no equivale a un paraíso. Nos arries- gamos a plantear que se trata de una interpretación que pone a salvo -al menos por momentos- esa expresión sitiada por lo "técnico" de las "políticas" y abusada por sus burócratas que han hecho de los derechos un servicio, y de los niños, las niñas y sus familias unos usuarios. En ese reino está desterrada toda taxonomía; se trata de un terreno que solicita nuestra disponibilidad para aprender-como dice Yolanda-, esto es, para caminarlo y construirlo ayudados por las brújulas ya disponibles porque -como es evidente- los lineamientos orientan, pero no son los que transforman las prácticas educativas.

Entonces, leer: baño de palabras que expresa respeto por la infancia -la propia y la de los otros-, modo de conferirle a cada ser humano que arriba al mundo "el derecho de ser un niño" (Korczak, 1993, p.42), de pertenecer a un reino en el que se practica ese gesto habilitador de una firma posible - porque es en la conjugación de letras, sonidos, movimientos, palabras, sentidos y lugares ofrecidos, donados y enseñados que puede crearse una firma, una huella singular para tener parte en el mundo común-. La infancia que nos concierne política y pedagógicamente no es solo la de los niños y las niñas, es también la de sus maestras, es la de cualquiera, inclusive la de quienes están conven- 
cidos de haberla superado. "Por adelantado que esté en la vida y por mucha lucidez que tenga sobre sí mismo, ninguno de nosotros termina nunca de pasar cuentas con su infancia, y aquel que crea que se ha librado de ella, quizá sea el más esclavo" (Meirieu,
2004, p. 18). Por lo anterior, agradecemos a Yolanda Reyes por decidirse a "andar por ahí", por labrar -junto a otros- el camino para expandir este reino de justicia y dignidad que es nuestra responsabilidad ofrecer a todos los niños y las niñas.

Nota

1. Agradecemos a Estefanía Vélez Arias por la transcripción, a Luisa Fernanda Acosta Castrillón por haber realizado una primera corrección y a Nancy Botero Areiza por acompañar las decisiones que permitieron darle una forma final a este texto.

2. Proyecto de investigación desarrollado entre 2016 y 2021 en el marco de la Convocatoria Programática del Comité para el Desarrollo de la Investigación -CODI-, de la Universidad de Antioquia.

3. Actual Viceministra de Educación Preescolar, Básica y Media. Coordinó entre 2012 y 2016 la Comisión Intersectorial de Primera Infancia de la Presidencia de la República y fue Subdirectora para la Infancia en la Secretaría de Integración Social de Bogotá.

\section{REFERENCIAS}

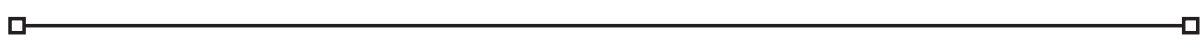

Korczak, J. (1993). El derecho del niño al respeto. México: Trillas.

Meirieu, P. (2004). El maestro y los derechos del niño. ¿Historia de un malentendido? Barcelona: Octaedro. 